\title{
Digital literacy \\ - a qualitative systematic review
}

\section{Andreas L. Tamborg}

\section{Ph.d.-stipendiat}

Institut for Læreruddannelsen, Københavns

Professionshøjskole/Institut for Læring og Filosofi, AAU

\section{Jonas Dreyøe}

\section{Ph.d.-stipendiat}

Ledelse, Organisation og Forvaltning Københavns

Professionshøjskole/Institut for Læring og Filosofi, AAU

\section{Simon Skov Fougt}

Lektor, Ph.d.

Institut for Læreruddannelsen, Københavns

Professionshøjskole 


\section{Abstract}

This paper is a qualitative systematic literature review that seeks to identify definitions and usages of the concept of digital literacy in recent research within elementary and primary education. Whereas it is widely acknowledged that digital literacy is an ambiguous term, this paper investigates how and why this is the case. In the paper, we identify nine categories of definitions and usages of the term and argue that this diversity can be explained as two tendencies: 1) the lack of definitions and explanations of how the term is used, and 2) the fact that digital literacy is studied within a wide range of different theoretical perspectives that each shape the conceptualization of the term. We conclude by conceptualizing a model of standpoints in the definitions of digital literacy which may function as a tool for future research of digital literacy.

\section{Introduction}

The increase of digitization has had, and is likely to continue to have, tremendous implications for teaching and learning in school contexts. Many of the recently developed innovative digital approaches to teaching such as MOOCSi, Flipped Classroom, and the pedagogical approaches developed in relation to $\mathrm{BYOD}^{\mathrm{ii}}$ or $\mathrm{CYOD}^{\mathrm{iii}}$ are closely interwoven with the increase of readily available technologies. The increase of digital technologies around us is by no means an isolated phenomenon that only takes place in educational contexts; it is perhaps better understood as a reflection of what is going on in the world outside school. Schools and education in general could be said to have a double role in their work with technology. Teachers, teacher educators, and educational researchers have an obligation to investigate and experiment with how technology may enrich existing approaches to teaching or the development of new approaches, because schools also have a responsibility to prepare students for living in a society characterized by ever-changing and developing digital technologies. The latter obligation is especially reflected in international policy programs such as 21 st century skills, as well as in in many national curriculum reforms (e.g., www.p21.org; Kinzer, 2010; Aesaert, Vanderlinde, Tondeur \& van Braak 2013); efforts in measuring students' abilities to use technology have already been made in, for example, ICILSiv. This research shows that it is commonly thought that young people are digitally native but that this belief needs to be revised (e.g., Bundsgaard, Pettersson \& Puck, 2014). Whether this is the case or not, there is a need to carefully reflect on what is required to navigate safely in a technology-rich society, whether inside or outside school contexts.

In recent years, several concepts have been coined to identify, articulate, and address these challenges more precisely. These concepts include, among others, ICT literacy, media literacy, computer literacy and digital literacy 
(Buckingham, 2006). Within education research, digital literacy is widely used (Bawden, 2009). It was originally defined by Gilster (1997) as:

"the ability to understand and use information in multiple formats from a wide range of sources when it is presented via computers. (...). Digital literacy likewise extends the boundaries of definition. It is cognition of what you see on the computer screen when you use the networked medium."

(p. 1-2)

This definition foregrounds cognition as a key element of digital literacy. However, since 1997 many researchers have added definitions of digital literacy that foreground other elements of digital literacy (for example, Bawden (2009), Søby (2003), Martin \& Grudziecki (2006)). This increased number of definitions with different foci have led to a term that is often referred to as ambiguous (Bawden, 2009).

The complexity of digital literacy practices has further increased since the domestication of the internet and the constant flow of new emerging digital technologies. This implies that a complex definition of literacy is needed to maintain the multiple practices, contexts and technologies related to digital literacy (Buckingham, 2006; 2015). However, this complexity fosters ambiguity, which constitutes a problem. The primary objective of this review is therefore to contribute to untangle this ambiguity by identifying how the term is ambiguous and to investigate possible explanations of why this is the case. We do this by investigating the variety of ways in which digital literacy is defined and used in research in elementary and primary education, and what the potential reasons for this variety could be, thereby addressing the following research question:

How is digital literacy defined and used in the research literature about primary and elementary education, and what are the potential reasons for the variety in definitions and usages?

We begin the paper by explaining our method, including how we searched and selected the papers and the resources we developed and used in this process. We then describe the findings of the review, which we organize in three sections. The first section describes nine tendencies identified in the papers related to digital literacy. In the second section, we identify missing definitions of digital literacy and a tendency to substitute digital literacy with another similar term, and we suggest that this is a significant reason for the confusion related to the term. In the third section, we show how the use of established definitions of digital literacy in combination with other types of theory constitutes another significant factor in the variety of definitions and usages of 
digital literacy. We conclude by presenting a conceptualization of standpoints in the definitions of digital literacy, which we argue can preserve the complexity of digital literacy while allowing an accumulation of research findings.

\section{Method}

This review is a qualitative systematic review (Grant \& Booth, 2009) with the purpose of exploring and possibly expanding our understanding of digital literacy. Qualitative systematic reviews are characterized by analyzing studies with a focus of exploring themes and constructs in and/or across literature within a specific area of research (Grant \& Booth, 2009). This review is therefore not oriented towards aggregating research results and/or highlighting a "best-practice," but is better characterized as an interpretive approach aiming at developing an overarching narrative of a research field or object (Grant \& Booth, 2009). Qualitative systematic reviews are a highly relevant approach in this context, which supports us in broadening the understanding of digital literacy.

\section{Search and selection of papers}

As stated above, the main objective of this paper is to investigate how digital literacy is defined, interpreted, and used in English educational research literature regarding elementary/primary schools. To identify relevant papers for this purpose, we conducted a search for peer-reviewed papers in four databases within educational research, including Academic Search Premier (110 hits), ERIC (48 hits), SCOPUS (68), and ORIA (13 hits), generating a total of 239 papers. The search was made from using the following string:("digital litera*") AND ("elementary school" OR "elementary education" OR "primary school" OR "primary education"). This is illustrated in Figure 1. Our search was not restricted to any time span, as the search process resulted in a number of papers that we considered manageable.

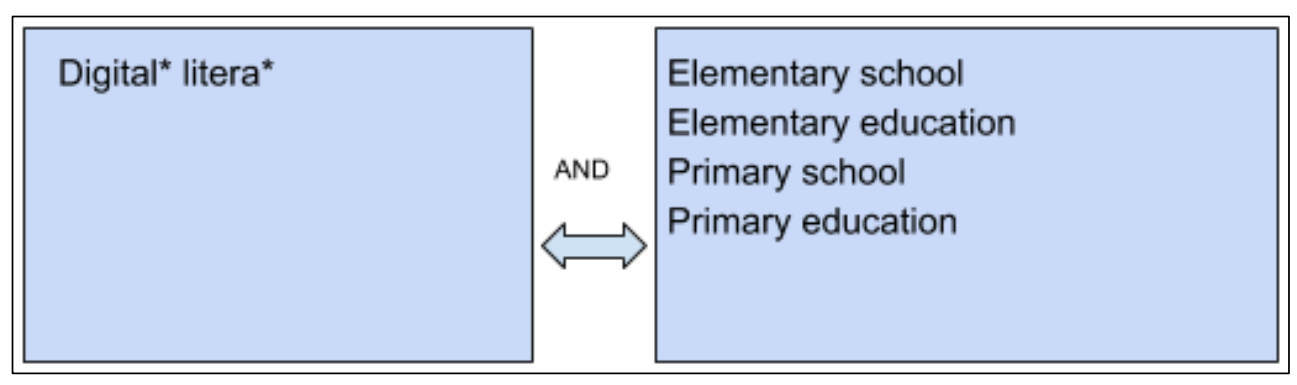

Figure 1. An illustration of the search string used to search for papers. 
Having identified these papers, we processed them by following the guidelines described in Higgins, Green, \& The Cochrane Collaboration (2017) to screen and select the papers to include in this review. These guidelines include merging the search results, examining titles and abstracts, retrieving full texts, examining full-text reports, and making the final decision of inclusion before continuing to data analysis. In this process, we excluded papers which without a doubt did not include digital literacy as a research object, for example, papers in which digital literacy only appeared as a minor relevant element and was not studied as such in the paper. In this process we also discarded papers that did not study digital literacy in primary and elementary education, but, for example, at universities or in other higher educational contexts. After having merged the search results into a single document, we continued this process by looking for duplicates in the search results from the different databases. This excluded a total of 44 papers that appeared in two or more of the four used databases. Hereafter, we examined the titles and abstracts of each paper with the primary objective of assessing whether the paper was about digital literacy in the context of elementary/primary education. This process excluded an additional 156 papers and left us with a total of 80 peer-reviewed papers about digital literacy in the context of elementary or primary education.

We then retrieved the 80 potentially relevant papers and codified them to systematize our analysis. For this, we developed and used a codification table consisting of fields representing the information to be retrieved from the papers for later analysis (see Figure 2). The fields were chosen to retrieve basic information about the paper and about how digital literacy was defined and used. Further, the fields entitled methods, geographical location of researcher(s)/research, and school level were chosen from a hypothesis that there might be stabilities in the variation of definitions of digital literacy according to these fieldsv .

\begin{tabular}{|l|l|l|l|l|l|l|l|}
\hline \hline Reference & $\begin{array}{l}\text { Purpose of } \\
\text { paper }\end{array}$ & Methods & $\begin{array}{l}\text { Geographi } \\
\text { cal location } \\
\text { of research }\end{array}$ & $\begin{array}{l}\text { School } \\
\text { level }\end{array}$ & $\begin{array}{l}\text { Definitions } \\
\text { and usage } \\
\text { of digital } \\
\text { literacy }\end{array}$ & $\begin{array}{l}\text { Applied or } \\
\text { developed } \\
\text { theories of } \\
\text { digital } \\
\text { literacy }\end{array}$ & $\begin{array}{l}\text { Relevant } \\
\text { (yes/no) }\end{array}$ \\
\hline
\end{tabular}

Figure 2. The developed codification table.

In codifying the papers according to these fields, a total of yet another 25 papers was eliminated because they 1) were written in another language than English, 2) did not contain the word digital literacy, or 3) because the study was not related to elementary/primary school, but, for example, higher education or kindergarten, leaving us a total of 55 papers that are 
included in this review. The selection process is represented in Figure 3 below.

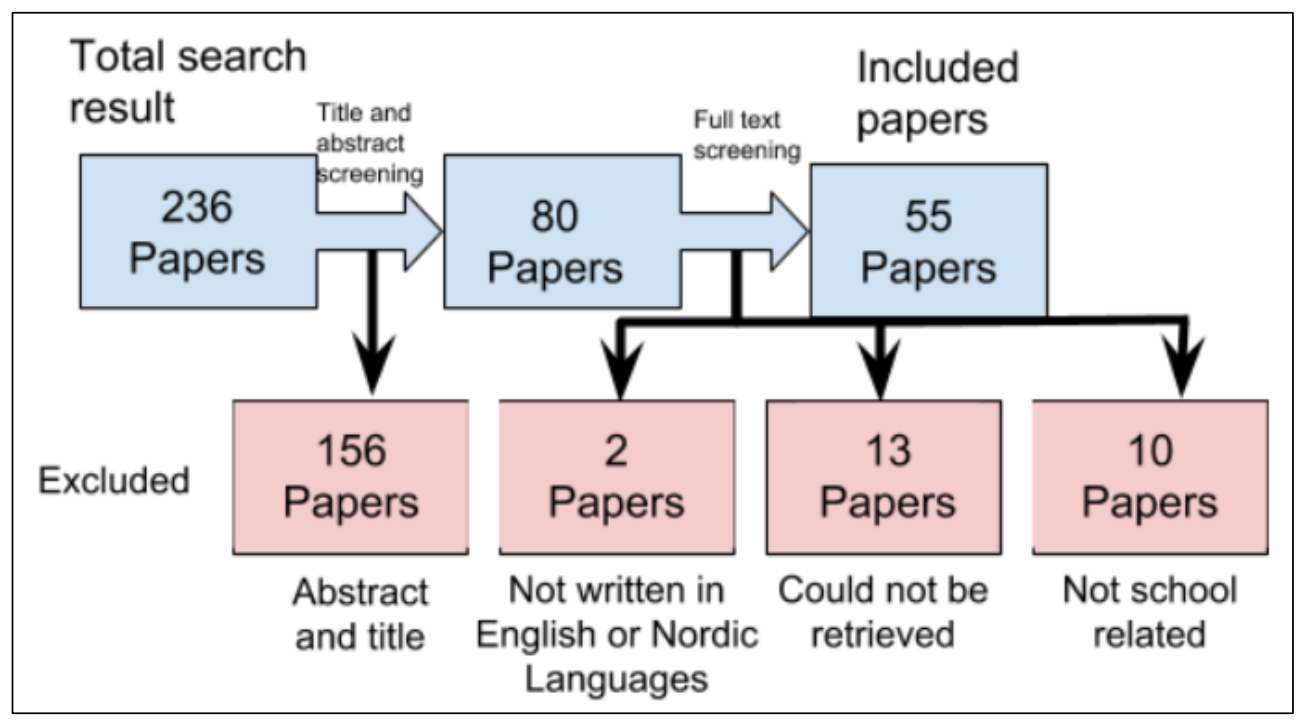

Figure 3. The process of screening papers.

After having read and described every paper according to our scheme, we began categorizing the definitions of the term digital literacy in a spreadsheetvi to identify the various definitions of the term.

\section{Findings}

In this section, we will present the findings of our review. The section is organized into two main subsections. The first subsection addresses the first half of our research question, namely how the research literature related to elementary and primary education defines and uses the term digital literacy and what differences we identify. We approach the answer to this question by describing eight different topics in the papers' definitions and usages of digital literacy. In the second subsection, we investigate and discuss the potential reasons why digital literacy is ambiguous and defined and used in many different ways. Here, we identify a lack of definitions and implicit methodological operationalizations of digital literacy as the first of two significant reasons for the ambiguity of the term. The second reason is the wide range of theoretical approaches to defining the concept.

\section{Varieties in the definitions and usages of digital literacy}

As described in the method section, we categorized how each of the papers defined and used digital literacy. The end-product of this process was a spreadsheet with nine nodes representing the categories that appeared 
among the papers, where papers could appear in more than one group. These categories are listed below.

1. Reading and writing with digital technology

2. Communication

3. Access to and acquaintance with digital tools

4. Attitude toward technology

5. Digital skills and knowledge

6. Social practice and classroom culture

7. Ethics

8. Critical thinking

9. No definition/no usage

In the following section, we will describe these categories in detail and provide empirical examples from the papers. We will address the ninth category entitled "no definition/no usage" in a separate section afterwards, as we identified this category as a potential explanation for some of the variety in how digital literacy was defined and used.

\section{Reading and writing with digital technology}

This category includes studies that primarily consider digital literacy as related to processing or communicating text through, in, or with digital technologies. Studies within this category were often based on the idea that new digital technologies imply new text modalities that redefine the practices of reading and writing (Gilster, 1997) and frequently define digital literacy by using the work of New London Group (1996) or Knobel and Lankshear (2006; 2008). An example of such studies is MackenHorarik (2009), who argued that the English language as a communication system is challenged by digitalization, and that the role of grammar is no longer a sufficient tool to help students navigate websites and social networking sites proficiently. This is a line of thinking which Merchant (2005) followed by stating that students' textual practices are being recontextualized from the variety of technology they use in their daily lives, such as mobile phones and computers (Merchant, 2005, p. 52). In his study from 2007, Merchant defined digital literacy as

"the study of written or symbolic representation that is mediated by new technology. Its prime concern would be the production and 
consumption of the verbal and symbolic aspect of screen-based texts"

(Merchant, 2007, p. 121)

Though some of these studies acknowledge digital literacy to transcend practices of reading and writing with digital technology, they are all characterized by foregrounding studies of communication of text as a key element of digital literacy.

\section{Communication}

The studies in this category emphasize that digital literacy involves communication in a broader sense than merely reading and writing. Casey and Bruce (2011) were rather explicit in this when arguing that digital literacy

"extends beyond reading and writing as usually conceived. Literacy implies the capacity to communicate meaning - from speaker to listener, from writer to reader, from creator to viewer" (Casey \& Bruce, 2011, p. 77)

Other studies such as Brown (2016) did not define digital literacy, but mentioned that
"the use of e-readers or similar devices offered young students ways to develop and/or enhance their digital literacies, which are essential for communication in a global world"
(Brown, 2016, p. 44)

The study by Hagge (2017) is another example, as digital literacy here was defined broadly as "related to skills associated with communication technologies (ICT)" (p. 154-155) and Kinzer (2010) who defined it as merely "the ability to communicate and to find and evaluate information critically" (p. 51). These studies contribute in expanding digital literacy to involve various kinds of information perhaps expressed most clearly by Casey and Bruce (2011) as the capacity to communicate meaning.

\section{Access to and acquaintance with digital tools}

Whereas the two categories above define digital literacy as the ability to do something with digital technology, papers within this category focus on the prerequisites of using technology, namely actors' access to and acquaintance with technology. This includes investigations of matters such as students' access to computers and internet connection and the extent of 
their acquaintance with using various software programs. Within this category, we find the study of Pombo, Carlos and Loureiro (2015) who investigated teachers' level of digital literacy through a survey in which teachers were asked to what extent they use ICT in their teaching (p. 15). Another example is Thorvaldsen, Egebjerg, Pettersen and Vavik (2011), who investigated students' digital literacy by measuring their self-reported abilities to chat on MSN, use Microsoft Word, and search information on the internet. Falkner, Vivian and Falkner (2014) is an example of an explicit definition of digital literacy as related to acquaintance with digital tools, namely as students' "familiarity with the tools and approaches to interact with technology" (p. 3). Though not defining digital literacy, Ravasco, et al. (2014) and Ravasco, Brigas, Reis, Fonseca, Mateus and Bolota (2015) also falls within this category as these studies both investigated digital literacy in a survey which included items such as: "Have you got a computer? Can you use a computer? Do you use the computer?" (Ravasco et. al. p, 3-8).

\section{Attitude towards technology}

The papers in this category use the term digital literacy to refer to students', teachers' or other relevant actors' view or stance towards digital technology, although none of the papers within this category explicitly define attitude towards technology as a component of digital literacy. Three studies nonetheless address actors' attitude towards digital technology as a key element of increasing their digital literacy, either by investigating it or seeking to change it. This is, for example, the case of Fernandez-Montalvo et. al. (2016), who designed an intervention for students specifically aimed at increasing their digital literacy understood as to "become more aware of how they use the internet" (p. 8). In a study of students' level of digital literacy, Thorvaldsen, Egeberg, Pettersen and Vavik (2011) screened the students for "PC anxiety/poor attitudes" (p. 313).

The study of Gruszczynska, Merchant and Pountney also deals with teacher-training students' attitude as an indicator of digital literacy, in that this explorative study investigated students' views on their usage of technology for educational practices (2013 p. 211).

\section{Digital skills and knowledge}

This category includes papers that define or use digital literacy to mean a set of skills or a certain knowledge of digital technology. The papers dealing with skills often cluster skills as the procedural element of digital literacy, whereas knowledge is referred to as a conceptual element. Some papers further specify the skills related to digital literacy as social media skills (Morgan, 2014), internet safety skills (Fernandez-Montalvo, Penalva, Irazabal \& Lopez-Goni, 2016; Lotherington \& Ronda, 2009) and 
instrumental skills in academic context (Cohen \& Tally, 2004) or leisure contexts (Vélez \& Zuazua, 2017).

In terms of media skills, Morgan (2014) argued that social media skills in particular are an important aspect of digital literacy as employers "currently value digital literacy and look to hire employees who are skilled in social media" (Morgan, 2014 p. 75). This paper did not, however, specify what social media skills involve, but only argues that digital skills can be developed by using social media such as Twitter. Lotherington and Ronda (2009) defined digital literacy as involving media skills, which in this case refers specifically to the ability to manipulate digital environments (p. 19) when designing and building computer games. This latter example demonstrates how a broad term such as media skills may refer to a very specific set of skills when it appears in a study in a particular context.

The fact that context plays a role for how digital literacy is defined is also illustrated in the study by Cohen and Tally (2004). This paper studied the role of technology in K-12 standards and argues that the integration of technology in the curriculum requires digitally-literate teachers. In this case, digitally-literate teachers is defined as someone with context-specific instrumental skills to utilize and evaluate subject-specific applications, such as software for doing math or reading (Cohen \& Tally, 2004, p. 7).

Context also played a big part in the work of Veléz and Zuazua, which argues that ICT requires digital literacy in many different contexts: "at relationship level, at communication level, at learning level, at curiosity satisfaction level, at entertainment and leisure level (Machargo, Luján, León, López \& Martín, 2003; Castellana, Sánchez, Graner \& Beranuy, 2007; Vélez \& Zuazua, 2017, p. 110). This quote illustrates that digital literacy involves context-specific skills for many different contexts.

The papers in the review refer to different kinds of knowledge that are important for being digitally literate, including conceptual knowledge (van Der Meij, 2012), procedural knowledge (Thorvaldsen, Egeberg, Pettersen \& Vavik, 2011), and knowledge about internet safety (Vélez, Olivencia, \& Zuazua, 2017). Others emphasize that knowledge is important to be digitally literate without specifying what is important. This is the case of AlQallaf and Al-Mutairi (2016), who investigated teachers' ability to develop their students' digital literacy through focus group interviews that evaluated their knowledge of and ability to identify student problems that could emerge when using blogs in their teaching (Al-Qallaf \& Al-Mutairi, 2016, p. 530). Similarly, Turculet and Turbule (2015) focus on the knowledge needed among teachers to build their students' digital literacy. This paper defined digital literacy as 
"the ability to understand and use information in multiple formats from a wide range of sources when presented with a digital device" (Turculet \& Turbule, 2015, p. 348)

and emphasized that teachers need knowledge about both the digital technology they use in their teaching and the specific content they teach with this technology to build the digital literacy of their students (Turculet \& Turbulure, 2015).

Some papers defined and used digital literacy as involving both skills and knowledge. van Der Meij (2012), for example, argued that many children know basic digital skills needed in modern society, such as how to use text processors and independently search and find information on the internet (van Der Meij, 2012, p. 1104). According to this author, such skills are superficial, fragile, and far from sufficient. Instead, such skills need to be combined with conceptual knowledge about how information on the internet has gotten there, and that students should be able to review the websites they visit "with a keen eye on their credibility" (van Der Meij, 2012).

Thorvaldsen, Egeberg, Pettersen and Vavik (2011) also emphasized that being digitally literate requires a combination of skills and knowledge of procedures in digital processes. This study investigated students' digital literacy through practical tests, surveys, and interviews. The practical tests investigated the students' abilities to use chat programs and other software programs, whereas the interviews addressed their level of knowledge of how to perform "basic" tasks on a computer, such as downloading music, sending email, etc. This study thereby both measured students' ability to perform tasks on a computer as well as their knowledge about these operations and capability of explaining them.

\section{Social practice and classroom culture}

The category entitled social practice includes papers that either define or use digital literacy to broadly refer to students' and/or teachers' practices with digital technologies in social contexts or fora. One example of this is Marty et al. (2013), a paper that did not define digital literacy explicitly, but investigated

\footnotetext{
"what digital literacy skills students employ as they engage in scientific inquiry activities in informal learning environments" and how "involving students as active participants in their own science education helps encourage the use of digital literacy skills"

(Marty et al., 2013, p. 416).
} 
Focusing on students' inquiry activities and how students participate in their education, this study thereby investigated digital literacy as a set of social practices within education. The study by Veléz and Zuazua (2017) is another study without a definition of digital literacy, but that nonetheless examined 3rd-6th graders' social behavior on the internet and with their mobile phones as an indication of their digital literacy. These usages of digital literacy thereby emphasize that it is related to the practices of a group of people using technology.

Some papers within this category explicitly define social practice as a key element of digital literacy, e.g., Tran (2016). In this paper, digital literacy involved "meaning making and participating in social practices around various kinds of digital texts" (Tran, 2016, p. 213). This is also the case in the study of Bhatt, DeRoock and Adams (2015) that conceptualized digital literacy as
"a shift in mind-set from one which perceives literacies as simply more 'technologized' due to new media, to one that acknowledges them as radically re-shaping and re-organizing societies" (Bhatt, DeRoock and Adams, 2015, p. 480).

This point is also found in Underwood, Parker and Stone (2013) who argued that informal learning contexts enabled students to learn
"how to coordinate their work activity in a complementary manner and how to incorporate each other's ideas productively with increasing tact and diplomacy"
(Underwood, Parker \& Stone, 2013, p. 490).

\section{Ethics}

This category includes papers with a definition of digital literacy that focuses on ethical integrity, responsibility, and principles when using digital technology. This is, for example, the case of Fernandez-Montalvo, Penalva, Irazabal \& Lopez-Goni (2016), for whom informing students about cyberbullying and how to deal with these kinds of situation is mentioned as an important part of building the digital literacy of primary school students. A study of Merchant (2007) also emphasized that digital literacy includes to

"learn about the power, responsibilities and ethical considerations that come into play in communicative settings. (...) examine and critique discourses that relate to wider social issues, power 
relationships, prejudices or inequities"

(Merchant, 2007, p. 123)

Another aspect that appeared as an ethical element of digital literacy was internet safety. One of the studies stressed that educational systems hold a responsibility to train students in how to navigate safely on the internet (Ybarra, Mitchell, Wolak \& Finkelhor, 2006) and another paper defined digital literacy as first and foremost related to this, namely as "a safe and responsible use of the internet" (Fernandez-Montalvo, Penalva, Irazabal \& Lopez-Goni, 2016, p. 1).

\section{Critical thinking}

The papers in this category associate digital literacy with the ability to critically, safely, and/or professionally navigate in a technology-rich information society in school contexts. Definitions within this category often involve some of the skills or the knowledge mentioned above (or a combination thereof) but tend to emphasize that being digitally literate is the ability to convert and combine them in a reflective and critical practice.

One example of papers within this category is Marty et. al. (2013). This paper, building on Hobbs (2011), defined digital literacy as involving the ability to analyze, evaluate, and critically engage with technology in learning environments (Marty et. al., 2013). Another example of this view is Pianfetti (2001), which suggested that digital literacy includes the ability to "process information from a variety of sources and formats so that she may be able to draw her own conclusions and create her own knowledge" as well as critical knowledge of how to assemble and produce digital products (Pianfetti, 2001, p. 256). Tosca and Ejsing-Duun (2017) is also placed in this category. These authors defined digital literacy to include the ability to appropriately use digital technologies to evaluate, synthesize, evaluate, and construct new knowledge, while at the same time being able to reflect upon this process (Tosca \& Ejsing-Duun, 2017, p. 241-242).

The sections above clearly reflects the already-known fact that digital literacy is used and defined in number of different ways. Besides reinforcing this fact, the section has illustrated that these differences can be described in eight different categories with which digital literacy is associated. As already mentioned, we stress that the categories are not mutually exclusive, but are analytical distinctions developed to separate the content of the definitions from one another. Some papers do include both ethics and communication or other combinations. As we will argue later, we suggest conceptualizing the differences among the categories in a more general way. The advantage of this approach is that such a 
conceptualization makes room for more and different categories of digital literacy than the ones we have identified in the empirical corpus of this review. Before this, we will, however, turn to the second part of the research question: the reasons why we see such variety in the definitions and usages of digital literacy.

\section{No definition/no usage}

In the section above, we distinguished between how digital literacy was defined and how it was used. We make this distinction because a substantial number of the papers either addressed digital literacy without defining it or defined digital literacy in one way but used it in another. Usage of the term digital literacy do therefore not necessarily imply ma definition of it. In fact, in 20 of the 55 papers in this review, digital literacy appeared in either the title, abstract, or keywords without being defined in the text. In some cases, the lack of a definition could be due to the marginal role that the concept played in the study. This could be the case in Owston, Wideman, Ronda and Brown (2009), who measured whether game development could improve the motivation and engagement of primary students. Here, digital literacy appeared as a finding, as the authors state that their "(...) project clearly gave students extended opportunities to develop digital literacy skills" (Owston, Wideman, Ronda \& Brown, 2009, p. 987) and thereby not as a key aspect of the research object. Such cases were uncommon, however, and even studies where digital literacy played a pivotal role sometimes did not include a definition of the term. This is the case with Hostovecky and Stubna (2012), which developed a course for primary students with the primary aim of developing their digital literacy. In spite of this aim, the paper did not include a definition of digital literacy and the methodology section merely stated that a questionnaire consisting of 23 questions regarding physics and computer science was answered by teachers (Hostovecky \& Stubna, 2012).

This lack of definitions creates a wide array of usages of digital literacy that often has no theoretical foundation. As we will argue in the following section, we have identified two main strands in the research papers that do not define digital literacy. We refer to these as tacit replacements and tacit definitions. The term tacit replacement refers to papers in which the term digital literacy appears in the title, abstract, as a keyword, or initially in the body text, but subsequently is replaced with another similar term (such as ICT literacy). The term tacit definitions refer to papers that don't define digital literacy, but where digital literacy nonetheless is transformed into a research design that still investigates or measures the digital literacy of a group of people in a specific way. In the following section, we give 
examples of how these phenomena appear in the reviewed papers and elaborate on the issues related to them.

\section{Tacit definitions}

Though digital literacy is not necessarily defined, some studies did nonetheless specify methodological approaches to investigate the digital literacy of a given group of people. We refer to this phenomenon as tacit definitions, because the choices and the reflections behind translating the term digital literacy into a concrete research design remains tacit. This is the case of a study by Ciampa (2017), who investigated three teachers' use of technology in their teaching for developing their students' digital literacy (Ciampa, 2017). Without defining digital literacy, the author explained how field notes from classroom observations, teachers' reflection blogs, and student product samples were used to generate the finding that a teacher

"provided her students real-world purposes for writing even as they developed their writing, digital literacy, and mathematical reasoning skills"

(Ciampa, 2017, p. 102)

The lack of a definition of literacy makes it unclear to the reader how exactly the concerned teacher managed to develop her students' digital literacy, and what this involves.

Another example of this phenomenon is found in a study by Lovin and Lambeth (2014). Their research investigated the impact of an online learning course with the purposes of improving the digital literacy practices of primary school students. Despite this paper focus explicitly on digital literacy, the term is only vaguely described in the following way:

\section{"Visual digital communication is one facet of digital literacy that is particularly valuable in art, as students need the ability to interpret visual images and apply them to their art products." (Lovin \& Lambeth, 2014, p. 15)}

This vague definition of digital literacy is then operationalized into specific foci for classroom observations of how students locate art resources, how they discuss in an online forum, and the like (Lovin \& Lambeth, 2014, p. 19).

Pombo, Carlos and Loureiro (2015) also did not define digital literacy but developed a questionnaire about how often teachers use ICT in their preparations of classes, which is used as a measure of the teachers' level of digital literacy (Pombo, Carlos \& Loureiro, 2015, p. 21-24). 
One of the issues emerging when researchers are operationalizing a concept into a research design without having defined this concept is that the definition of digital literacy at best remains implicit and can only be retrieved from interpreting the methodological instruments. Tacit reflections of how it is operationalized represent a great threat in building solid, research-based knowledge about digital literacy and its related issues.

\section{Tacit replacements}

The second strand of papers that do not define digital literacy are characterized by replacing digital literacy with another, often similar, term. We refer to this category as tacit replacements because digital literacy in these cases is tacitly translated into another term without explanation. These terms include digital media literacy (Machado-Casas, Sánchez \& Ek, 2014), digital competencies (Perez-Escoda \& Rodriguez-Conde, 2015), 21st century skills (Price-Dennis, Holmes \& Smith, 2015), Digital Divide (Machado-Casas, Sánchez \& Ek, 2014) and ICT literacy (Chang \& Tsou, 2006; Thorvaldsen, Egeberg, Pettersen \& Vavik, 2011). In these studies, the term digital literacy appeared in either the title of the paper, the abstract, or as a keyword, but another concept was used in the body text.

The study of Machado-Casas, Sánchez and Ek (2014) is, for example, entitled "The Digital Literacy Practices of Latina/o Immigrant Parents in an After-School Technology Partnership," but the term digital literacy only appeared in the title whereas the study investigated the digital divide of Latino students. Similarly, in the study of Chang and Tsou (2006), the abstract stated that the primary aim of the paper was to "understand the current status of the character of digital literacy in Taiwan" (Chang \& Tsou, p. 191), but digital literacy was replaced with information literacy in the rest of the paper.

The phenomena described above constitute two potential reasons why digital literacy is an ambiguous term, in that studies of this kind apply more or less random definitions or usages of the term that happens to fit the context of the given study. These phenomena are a problem in that they make it difficult to accumulate knowledge of digital literacy, as it is unclear what they refer to. As we will describe in the following section, there is yet another potential reason for the variety of definitions and usages of digital literacy, namely how the term is studied theoretically. In the following section, we will illustrate how the use of different theoretical resources imply substantial differences in how the concept is defined and used. 


\section{Theoretical approaches for studying digital literacy practices}

The wide range of differences in the definition and usage of digital literacy is remarkable considering that the vast majority of the papers define the term by using established frameworks, most frequently Lankshear and Knobel (2006; 2008), New London Group (1996), or Martins (2008) (see, for example, (Gruszczynska, Merchant \& Poutney, 2013; Burnett, 2009; Merchant, 2005)). In the papers, these frameworks seldom stood alone, but were often combined with theories of learning, identity theories, or socialization theories. In this section, we show how such combinations of frameworks may imply that established definitions of digital literacy can be subordinated to, or re-framed within, other theoretical frameworks. This translates into shifts in how digital literacy is understood and studied, which contributes to broadening the variety of how digital literacy is defined and used even further.

An example of this is a study by Bjørgen and Egstad (2015) that drew on Lankshear and Knobel's $(2006 ; 2008)$ definition of digital literacy as the

"socially recognized ways of generating, communicating and
negotiating meaningful content through the medium of encoded
texts within contexts of participation"
(Lankshear \& Knobel, 2006, p. 64 in: Bjørg \& Erstad, 2015, p. 115)

In their study, the authors combined this definition with theories of identity theory as positional (Moje, Luke, Davies, \& Street, 2009) to focus on "how students' conceptions of digital literacies and their positional identities are defined across school and home" (Bjørgen \& Erstad, 2015, p. 113). Consequently, this paper gave particular emphasis to students' shifting sense of agency in different contexts (in this case, school and leisure) and viewed these different contexts as opportunities for experiencing digital literacy practices (Bjørgen \& Erstad, 2015). This conceptualizing of digital literacy from a combination of several theoretical sources thereby opened the opportunity to study digital literacy understood as differences among students' perceptions of using technology in an outside-school setting. Such a study can provide important insights on the relation between students' use of technology in different contexts, but it also broadens the understanding of Lanskhear and Knobel's (2006) original definition of digital literacy.

Other examples are the studies by Shin and Seger (2016) as well as Underwood, Parker and Stone (2016). The common characteristic of these two papers is that they combined theories of digital literacy with 
sociological perspectives based on the work of Bourdieu (1990;1991). The study of Shin and Seger (2016) defined digital literacy based on the New London Group (1996) as "the social practice and functional skills related to making meanings in digital environments" (Shin \& Seger, 2016, p. 313). Using the work of Bourdieu (1990;1991), Shin and Seger (2016) argued, however, that digital literacy cannot be studied in isolation from the upbringing and social background of the individual student. Instead, digital literacy must be considered a product of cultural, social, political, and material capital of the student and their parents (Shin \& Seger, 2016, 311). Therefore, this research is particularly interested in studying how parents of the students participated in their children's learning processes, in this case digital blog postings that were a part of the course.

Also building on Bourdieu (1991), Underwood, Parker and Stone suggested that digital literacy practices must be studied as "digital literacy habitus" (Underwood, Parker \& Stone, 2013, p. 483). According to these researchers, a digital literacy habitus both involved instrumental skills involving various technologies, such as the ability to

"carry out internet research - how to locate and glean relevant
information and how to interpret the information they had
collected and accommodate it for their own project"
(Underwood, Parker \& Stone, 2013, p. 490)

and the ability to collaborate and negotiate with peers in digital environments (Underwood, Parker \& Stone, 2013). Building on Bourdieu (1991), such a habitus is considered crucial for students' future opportunities of performing well in academic contexts. These authors also argued that schools have an important role in equalizing an otherwise uneven distribution of the skills of using and collaborating with technologies, which they consider a requirement to perform well in the educational system (Underwood, Parker \& Stone, 2013).

Another example of how digital literacy is framed within a specific theoretical framework is a study of Casey and Bruce (2011). This paper sought to develop a pedagogy that situates digital literacy as an integral part of another pedagogy based on pragmatic educational philosophy (Dewey, 1991; 1997) entitled "The Inquiry Cycle" (Casey \& Bruce, 2011). This study investigated the practices and ways of participating in lessons that are enabled when an approach called Inquiry Cycle is implemented in a technology-rich classroom (Casey \& Bruce, 2011). This paper drew explicitly on both Lankshear and Knobel (2008) and New London Group's (1996) definition of digital literacy as 
"activities [that] occur in social, cultural and technological contexts, and are created and sustained by contextual factors literacy is a social product and, like language itself, is interactive and dynamic"

(New London Group, 1996 in: Casey \& Bruce, 2011, p. 77)

Casey and Bruce (2011) however argued that the "Inquiry Circle" pedagogy is based on principles that require an understanding of digital literacy within pragmatic philosophy. Therefore, the authors defined digital literacy in the following way:

"Literacy is best understood through the concept of participation. Literacy enables participation, and new technologies give rise to new forms of participation, and hence new literacies" (Casey \& Bruce, 2011, p. 78)

And further:
"Digital literacy in primary schools involves pupils and teachers using digital technology to enable, sustain and enrich all aspects of the inquiry cycle of learning as: ask, investigate, create, discuss and reflect"
(Casey et al., 2009, p. 7)

This example illustrates how a widely-accepted definition of digital literacy can easily be shaped and shift meaning when combined with theoreticallyrooted pedagogical aims.

All of the examples above are well-suited to demonstrate the complexity of the research literature about digital literacy. They also help to identify that the complexity regarding the term digital literacy is not only due to the variety of definitions of the term. The complexity is also, and perhaps more implicitly, related to the theoretical resources with which established definitions of digital literacy are combined.

\section{Towards a conceptualization of standpoints in definitions of digital literacy}

In the findings section above we have identified a broad variety in how digital literacy is defined and used in the research literature in the context of elementary and primary education. This finding is not new or surprising, as the term is often explicitly referred to as ambiguous and broad (Stepic, 2013; Aesaert, Vanderlinde, Tondeur \& van Braak, 2013; Hagge, 2017; Underwood, Parker \& Stone, 2013; Merchant, 2009). Unlike the dominant 
perspective in the literature about digital literacy, we do not, however, think the broadness and multiple meanings of digital literacy is a problem that needs to be overcome. On the contrary, there might also be advantages of making efforts in maintaining and perhaps continuing to broaden our perspectives on digital literacy.

So far, we have identified three potential sources of these varieties: The various topics that digital literacy is related to, the fact that digital literacy is often not defined or substituted with another similar term, and that established definitions of digital literacy are combined with theories from other fields. Studies that did not explicitly define digital literacy represent a genuine threat to building a research-based foundation of knowledge about digital literacy, as it is unclear exactly what the term covers. Explicit variations in how the term is defined and used, however, enables research to capture the complexity of digital literacy and the many actors and contexts that can be relevant to include in studies of this phenomenon. Such a variety in definitions contributes to studying digital literacy from different angles using different theoretical resources and can broaden our knowledge of what, who, and where digital literacy practices are performed. In order to inform the choice of definitions and usages of digital literacy for research, we, however, believe that a conceptualization of the opportunities at hand would be beneficial. Such a conceptualization could help systematize the accumulation of knowledge and research findings related to digital literacy. Based on the variety of definitions and usages of the term, we will therefore introduce a model that illustrates how the definitions relate to one another. Though this model first and foremost is based on empirical findings, it is our hope that it will constitute a road map that can support definitions of digital literacy prospectively.

Figure 4 illustrates a model consisting of two axes with two poles. We refer to these dimensions as interpersonal/intrapersonal and technocentric/human-centric. The purpose of structuring our findings according to this model is that it allows us to map the definitions and usages of digital literacy and describe how they relate to each other. 


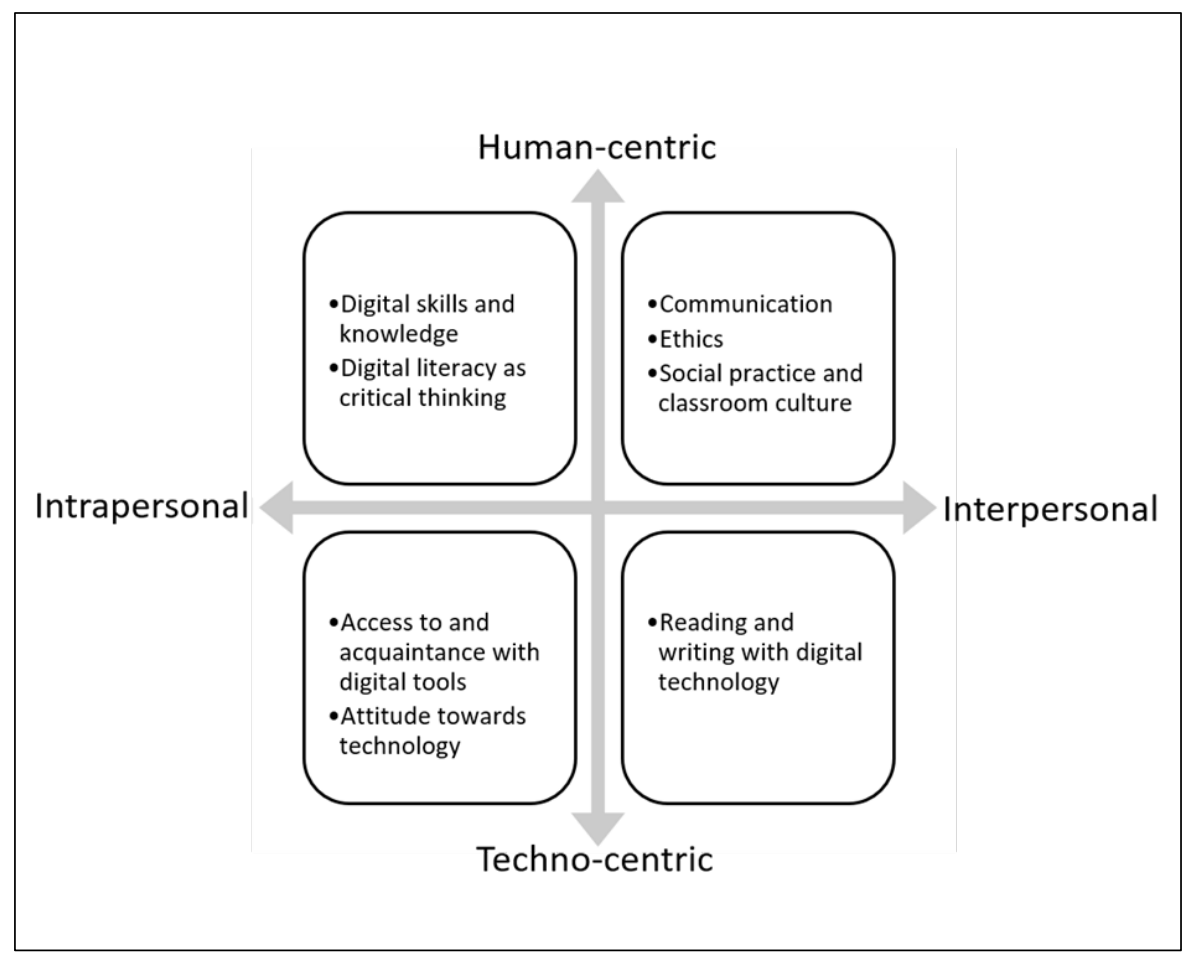

Figure 4. A model illustrating the eight categories placed in four quadrants on the axes intrapersonal/interpersonal and human-centric/techno-centric.

In the following section, we will explain the axes and their empirical foundation in more detail.

The vertical axis: the techno-centric/human-centric dimension The techno-centric end of the vertical axis represents papers that infer a definition of digital literacy from what new technology requires of a proficient user. An example of this type of definition is found in the work of Merchant (2007) on how we should understand digital literacy in relation to writing. In this paper, he defined digital literacy as

\section{"written or symbolic representation that is mediated by new technology. Furthermore, the specific affordances of digital literacy could be conceptualized as a product of the technological means of its production and consumption" (Merchant, 2007, p. 121)}

The latter sentence especially illustrates the key role of the technology in digital literacy and the underlying conception that technology brings relatively predictable new changes to which we must adapt. 
The top end of the vertical axis represents a human-centric perspective on digital literacy. This perspective defines digital literacy as the human capacities and values we should strive to maintain in a technology-rich society. This includes definitions and usages of digital literacy that are closely connected to how to communicate properly using technology, how to avoid cyberbullying, or otherwise maintain ethically correct behavior when using digital technology. An example of such a definition is found in the work of Vélez, Olivencia and Zuazua (2017), who defined digital literacy and individual's ability to

"build a digital identity in the net as an independent, cultivated and democratic citizen. Digital literacy should also take into account every relational process linked to conviviality that takes place in the digital world" (Vélez, Olivencia \& Zuazua, 2017, p. 616)

This definition foregrounds the ability to build an identity in a context of digital technology conviviality, thereby emphasizing the practices with digital technology rather than the technology itself. Another definition that clearly falls within this category is found in the work of Shin and Seger (2016), who defined digital literacy as "discursive practices that are shaped by one's social, cultural, and political access (p. 311)”.

\section{The horizontal axis: the intrapersonal and interpersonal dimension}

The intrapersonal dimension represents definitions and usages of digital literacy as intrinsic capabilities of individuals or a group of individuals in relation to digital technology. The definitions at this end of the axis often tend to measure or evaluate the level of digital literacy against a predefinition of digital literacy (either qualitatively or quantitatively, e.g., Sun, Wang \& Liu, 2017; Perez-Escoda, Castro-Zubizarreta \& Fandos Igado, 2016; Pombo, Carlos \& Loureiro, 2015; Fernandez-Montalvo, Penalva, Irazabal \& Lopez-Goni, 2016, Thorvaldsen, Egeberg, Pettersen \& Vavik, 2011; Bjørgen \& Erstad, 2015). A typical example of such a usage of digital literacy is the study by Meneses, Fàbregues, Rodríguez-Gómez and Ion (2012), who investigated teachers' digital literacy from their

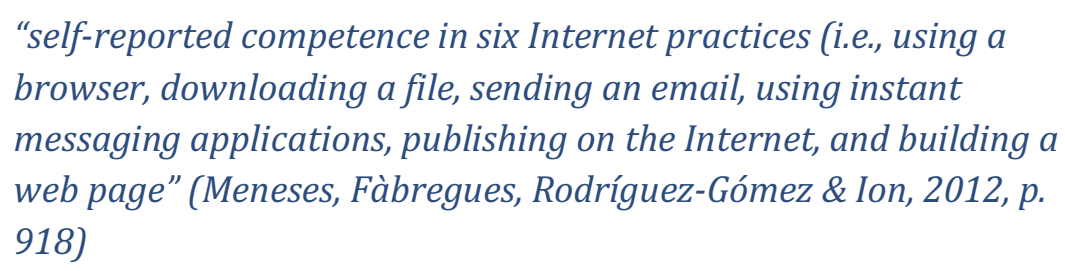

In this way, digital literacy is measured as an inherent capability of the individual teacher. 
The interpersonal end of the horizontal axis defines or uses digital literacy as actors' abilities to apply their capacities in a specific context and in relation to other people. The interpersonal dimension does therefore often include intrapersonal capacities, but always subordinates these to an interpersonal ability or context. Unlike the intrapersonal perspective, papers within this end of the horizontal axis tend to exploratively investigate digital literacy practices, often by using qualitative methods such as observations or other ethnographic approaches (see e.g. Casey \& Bruce, 2011; Bhatt, de Roock \& Adams 2015; Merchant, 2009).

\section{Ways forward}

The model affords several different usages. Before addressing the usages, we must make the point of departure clear. The axes are empirically generated dichotomies that represent poles and not a continuum. It is possible to challenge this in future research and is in by no means meant to be comprehensive. Besides depicting and placing the empirically generated definitions and usages of digital literacy, the model also shows how definitions are based on different assumptions, thus making it clear that it is not a trivial task of comparing two digital literacy conceptions based on different assumptions. Another potential usage of the model is that it can assist in identifying and articulating what is meant by the term digital literacy. In this way, the model allows research findings about digital literacy to accumulate without de-legitimizing some definitions or usages of the term over others.

As we have illustrated in Figure 4, the model leaves us with four quadrants that represent combinations of positions between the vertical and horizontal axes. The model thereby allows us to place the papers in the model according to which of the nine categories their definition and/or usage of digital literacy relates to, which we have already done in Figure 4.

\section{Conclusion}

The purpose of this paper has been to investigate how digital literacy is defined and used in the research literature in the context of primary education, and to identify reasons for the variety of definitions and usages. We have described the different definitions and usages of the term through eight categories. Further, we have identified two main reasons for this substantial variety of usages and definitions, namely a widespread tendency for papers to not include a definition of the term and that digital literacy is studied from many theoretical standpoints. Contrary to the view of many researchers, we do not, however, consider the variety of definitions and usages of the term to be an unconditional problem. On the 
contrary, the broadness of the categories related to digital literacy illustrate the complexity of the term and the multiple contexts in which it may appear. If the complexity remains implicit, however, it represents a threat to accumulating knowledge about digital literacy. To preserve the complexity without simultaneously legitimizing some definitions over others, this paper presents a model that can serve the discussion of which aspects of digital literacy a given study could benefit from focusing on. It is our hope that this model can help researchers and practitioners in accumulating knowledge about digital literacy based on explicit and coherent definitions and usages of the term.

\section{References}

Aesaert, K., Vanderlinde, R., Tondeur, J., \& van Braak. J. (2013). The content of educational technology curricula: a cross-curricular state of the art. Educational Technology Research and Development, 61, 1, 13.

Al-Qallaf, C. L., \& Al-Mutairi, A. S. R. (2016). Digital literacy and digital content supports learning: The impact of blogs on teaching English as a foreign language. Electronic Library, 34, 3, 522-547.

American Library Association (ALA) (2013). Digital Literacy, Libraries, and Public Policy, Report of the Office for Information Technology Policy's Digital Literacy Task Force, available at: www.districtdispatch.org/wpcontent/uploards/2013/01/2012_OITP_digitalreport_1_22_13.pdf.

Bawden, D. (2001). Information and digital literacies: a review of concepts. Journal of Documentation, 57, 2, 218-259.

Bhatt, I., de Roock. R., \& Adams, J. (2015). Diving deep into digital literacy: emerging methods for research. Language and Education, 29, 6, 477492.

Bjørgen, A. M., \& Erstad, O. (2015). The connected child: tracing digital literacy from school to leisure. Pedagogies: an International Journal, 10, $2,113-127$.

Bourdieu, P. 1990. The Logic of Practice. Stanford, CA: Stanford University Press.

Bourdieu, P. (Ed.). (1991). Language and symbolic power. Cambridge, MA: Harvard University Press.

Brown, S. (2016). Young Learners' Transactions With Interactive Digital Texts Using E-Readers. Journal of Research in Childhood Education, 30, 1, 42-56.

Buckingham, D. (2015). Defining digital literacy: What do young people need to know about digital media? Nordic Journal of Digital Literacy 2015, 4, 21-34. 
Bundsgaard, J., Pettersson, M., \& Puck, M. R. (2014). Digitale kompetencer It i danske skoler i et internationalt perspektiv. Aarhus, DK: Aarhus Universitetsforlag.

Burnett, C. (2009: That's more like how they know me as a person: one primary pre-service teacher's stories of her personal and \& professional digital practices. Literacy, 43, 2, 75-82.

Casey, L., \& Bruce, B. C. (2011). The Practice Profile of Inquiry: Connecting Digital Literacy and Pedagogy. E-learning and Digital Media, 8, 1, 76-85.

Casey, L., Bruce, B.C., Martin, A., Shiel, G., Brown, C., Hallissy, M. et al. (2009). Digital Literacy: new approaches to participation and inquiry learning to foster literacy skills among primary school children. Dublin: Centre for Research and Innovation in Learning and Teaching, National College of Ireland. http://hdl.handle.net/2142/9765.

Ciampa, K. (2017). Building Bridges Between Technology and Content Literacy in Special Education: Lessons Learned From Special Educators' Use of Integrated Technology and Perceived Benefits for Students. Literacy Research and Instruction, 56, 2, 85-113.

Cohen, M., \& Tally, B. (2004). New Maps for Technology in Teacher Education: After Standards, Then What? Journal of Computing in Teacher Education, 21, 1, 5-9.

Dewey, J. (1991/1938). Experience and Education, in J.A. Boydston (Ed.) John Dewey: the latter works, 1938-1939, vol. 13. Carbondale: Southern Illinois University Press.

Dewey, J. (1997/1910). How We Think. New York: Dover.

Dowdall, C. (2009). Impressions, improvisations and compositions: reframing children's text production in social network sites. Literacy, $43,2,91-99$.

Falkner, K., Vivian, R., \& Falkner, N. (2014). The Australian digital technologies curriculum: Challenge and opportunity. Conferences in Research and Practice in Information Technology Series, 148, 3-12.

Fernandez-Montalvo, J., Penalva, A., Irazabal, I., \& Lopez-Goni, J. J. (2017). Effectiveness of a digital literacy programme for primary education students. Cultura Y Educacion, 29, 1, 1-30.

Gilster, P. (1997). Digital fusion: defining the intersection of content of communications. N. A. Martin \& D. Madigan (Eds.), Digital literacies for learning (p. 42-50). London: Facet Publishing.

Grant, M. J., \& Booth, A. (2009). A typology of reviews: an analysis of 14 review types and associated methodologies. Health Information and Libraries Journal, 26, 2, 91-108. 
Gruszczynska, A., Merchant, G., \& Pountney, R. (2013). "Digital Futures in Teacher Education": Exploring Open Approaches towards Digital Literacy. Electronic Journal of E-Learning, 11, 3, 193-206.

Hagge, J. (2017). Scratching Beyond the Surface of Literacy: Programming for Early Adolescent Gifted Students. Gifted Child Today, 40, 3, 154-162.

Higgins, J. P. T., Green, S., \& The Cochrane Collaboration. (2017). Cochrane handbook for systematic reviews of interventions. Chichester: WileyBlackwell.

Hobbs, R. (2011). "Empowering Learners with Digital and Media Literacy." Knowledge Quest 39 (5): 12-17.

http://http://aasl.metapress.com/content/r077370r202254m1/.

Hostovecky, M., \&Stubna, J., \&. (2012). Development of digital literacy in technical subjects at primary schools. IEEE 10th International Conference on Emerging eLearning Technologies and Applications, 139141.

Kinzer, C. K. (2010). Focus on Policy Considering Literacy and Policy in the Context of Digital Environments. Language Arts, 88, 1, 51.

Lankshear, C., \& Knobel, M. (2006). New literacies: Everyday practices and classroom learning. Maidenhead: Open University Press.

Lankshear, C., \& Knobel, M. (2008). Digital literacies: Concepts, policies and practices. New York: Peter Lang.

Lotherington, H., \& Ronda, N. S. (2009). Gaming Geography: Educational Games and Literacy Development in the Grade 4 Classroom. Canadian Journal of Learning and Technology, 35, 3.

Machado-Casas, M., Sánchez, P., \& Ek, L. D. (2014). The Digital Literacy Practices of Latina/o Immigrant Parents in an After-School Technology Partnership. Multicultural Education, 21, 28-33.

Macken-Horarik, M. (2009). Navigational Metalanguages for New Territory in English: The Potential of Grammatics. English Teaching: Practice and Critique, 8, 3, 55-69.

Martin, A. \& Grudziecki, J. (2006). DigEuLit: Concepts and Tools for Digital Literacy Development, 5:4, 1-19, DOI: 10.11120/ital.2006.05040249

Martin, A. (2008). "Digital Literacy and the Digital Society." In Vol. 30 of Digital Literacies: Concepts, Policies and Practices, edited by Colin Lankshear and Michele Knobel, 151-176. New York: Peter Lang.

Marty, P. F., Alemanne, N. D., Mendenhall, A., Maurya, M., Southerland, S. A., Sampson, V., Douglas, I., Schellinger, J. (2013). Scientific inquiry, digital 
literacy, and mobile computing in informal learning environments. Learning Media and Technology, 38, 4, 407-428.

Meneses, J., Fàbregues, S., Rodríguez-Gómez, D., \& Ion, G. (2012). Internet in teachers' professional practice outside the classroom: Examining supportive and management uses in primary and secondary schools. Computers \& Education, 59, 3, 915-924.

Guy, M. (2005). Digikids: Cool Dudes and the New Writing. E-learning and Digital Media, 2, 1, 50-60.

Merchant, G. (2007). Writing the future in the digital age. Literacy, 41, 3, 118-128.

Merchant, G. (2009). Literacy in virtual worlds. Journal of Research in Reading, 32, 1, 38-56.

Mirian, C.-R. (2016). Developing Skills in Digital Contexts: Video games and Films as Learning Tools at Primary School. Games and Culture, 11, 5, 463-488.

Moje, E. B., Luke, A., Davies, B., \& Street, B. (2009). Literacy and identity: Examining the metaphors in history and contemporary research. Reading Research Quarterly, 44(4), 415-437.

Morgan, H. (2014). Focus on Technology: Enhancing Instruction and Communication with Twitter. Childhood Education, 90, 1, 75-76.

New London Group. (1996). A pedagogy of multiliteracies: Designing social features. Harvard Educational Review, 66(1), 60-92.

Niemi, H., \& Multisilta, J. (2016). Digital Storytelling Promoting TwentyFirst Century Skills and Student Engagement. Technology, Pedagogy and Education, 25, 4, 451-468.

Owston, R., Wideman, H., Ronda, N. S., \& Brown, C. (2009). Computer Game Development as a Literacy Activity. Computers \& Education, 53, 3, 977 989.

Perez-Escoda, A., Iglesias-Rodriguez, A., Sanchez-Gomez, M. C. (2016). Nurturing digital citizenship: Teachers and Students Facing Digital Competences. 4th International Conference on Technological Ecosystem for Enhancing Multiculturality, TEEM 2016, 631-636, Acm International Conference Proceeding Series.

Perez-Escoda, A., Castro-Zubizarreta, A., \& Fandos-Igado, M. (2016). Digital skills in the Z generation: Key questions for a curricular introduction in primary school. Comunicar, 24,49, 71-79. 
Pianfetti, E. S. (2001). Focus on Research: Teachers and Technology: Digital Literacy through Professional Development. Language Arts, 78, 3, 255262.

Pombo, L., Carlos, V., \& Loureiro, M. J. (2015). Edulabs for the Integration of Technologies in Basic Education - Monitoring the AGIRE Project. International Journal of Research in Education and Science, 2,1, 16.

Price-Dennis, D., Holmes, K. A., \& Smith, E. (2015). Exploring Digital Literacy Practices in an Inclusive Classroom. The Reading Teacher, 69, 2, 195-205.

Purcell, M. (2012). Twitter tips and tricks for your library and classroom. Library Media Connection, 31(3), 46-47.

Ravasco, C., Brigas, C., Reis, C., Fonseca, C. Mateus, J \& Cordeiro, U. (2014). ICT'S importance in primary schools - parents and students' perceptions. Proceedings of EDULEARN14 CONFERENCE 7TH-9TH JULY, Barcelona, Spain.

Ravasco, C., Brigas, C., Reis, C., Fonseca, C. Mateus, J \& Bolota, U. (2015). Perceptions of ICT use in Guarda's primary schools. Proceedings of INTED2015 Conference 2nd-4th March 2015, Madrid, Spain

Shin, D., \& Seger, W. (2016). Web 2.0 Technologies and Parent Involvement of ELL Students: An Ecological Perspective. The Urban Review: Issues and Ideas in Public Education, 48, 2, 311-332.

Sun, K.-T., Wang, C.-H., \& Liu, M.-C. (2017). Stop-motion to Foster Digital Literacy in Elementary School. Comunicar, 25, 51.

Thorvaldsen, S., Egeberg, G., Pettersen, G. O., \& Vavik, L. (2011). Digital Dysfunctions in Primary School: A Pilot Study. Computers \& Education, $56,1,312-319$.

Tosca, S., \& Ejsing-Duun, S. (2017). Design thinking and imitation in an educational setting. Digital Creativity, 28, 3, 240-253.

Turculet, A. \& Turbulure, C. (2015). Digital Literacy Challenges in the context of contemporary education. Proceeding from the 11th International Scientific Conference eLearning and Software for Education, Bucharest, April 23-24, 2015, 346-353.

Tran, K. M. (2016). "Her Story Was Complex": A Twine Workshop for Tento Twelve-Year-Old Girls. E-learning and Digital Media, 13, 212-226.

Tyner, K. (1998). Literacy in a digital world. London: Lawrence Erlbaum Associates Publishers. 
Underwood, C., Parker, L., \& Stone, L. (2013). Getting it together: Relational habitus in the emergence of digital literacies. Learning, Media and Technology, 38, 4, 478-494.

van der Meij, H. (2012). E-learning in elementary education. In Z. Yan (Ed.), Encyclopedia of Cyber Behavior (pp. 1096-1110). Hershey: PA: Information Science Reference. DOI: 10.4018/978-1-4666-03158.ch090

Vélez, A. P., \& Zuazua, I. I. (2017). Digital Literacy and Cyberconvivencia in Primary Education. Procedia - Social and Behavioral Sciences, 237, 2, 110-117.

Vélez, A. P., Olivencia, J. J. L., \& Zuazua, I. I. (2017). The Role of Adults in Children Digital Literacy. Procedia - Social and Behavioral Sciences, 237, 2, 887-892.

Ybarra, M. L., Mitchell, K. J., Wolak, J., \& Finkelhor, D. (2006). Examining characteristics and associated distress related to Internet harassment: findings from the Second Youth Internet Safety Survey. Pediatrics, 118, 4, 1169-77.

\footnotetext{
i Massive Open Online Courses

ii Bring Your Own Device

iii Choose Your Own Device

iv International Computer and Information Literacy Study, http://www.iea.nl/icils

$\checkmark$ The completed table is accessible at

https://www.researchgate.net/publication/327395670 Analysis sheet of genbes

krivelser in digital literacy

vi This spreadsheet is also accessible at

https://www.researchgate.net/publication/327395498 Beskrivelser af pap

ers
} 